\title{
Article \\ Recurrent Herpes Simplex Virus Type 1 (HSV-1) Infection Modulates Neuronal Aging Marks in In Vitro and In Vivo Models
}

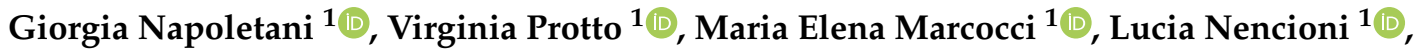 \\ Anna Teresa Palamara ${ }^{1,2,+} \mathbb{D}$ and Giovanna De Chiara ${ }^{3, *,+} \mathbb{D}$
}

1 Department of Public Health and Infectious Diseases, Sapienza University of Rome, Laboratory Affiliated to Istituto Pasteur Italia-Fondazione Cenci Bolognetti, 00185 Rome, Italy; giorgia.napoletani@uniroma1.it (G.N.); virginia.protto@uniroma1.it (V.P.); mariaelena.marcocci@uniroma1.it (M.E.M.); lucia.nencioni@uniroma1.it (L.N.); annateresa.palamara@uniroma1.it (A.T.P.)

2 Department of Infectious Diseases, Istituto Superiore di Sanità, 00161 Rome, Italy

3 Institute of Translational Pharmacology, National Research Council (CNR), 00133 Rome, Italy

* Correspondence: giovanna.dechiara@ift.cnr.it

+ Co-last authors.

\section{check for}

updates

Citation: Napoletani, G.; Protto, V.; Marcocci, M.E.; Nencioni, L.;

Palamara, A.T.; De Chiara, G. Recurrent Herpes Simplex Virus Type 1 (HSV-1) Infection Modulates Neuronal Aging Marks in In Vitro and In Vivo Models. Int. J. Mol. Sci. 2021, 22, 6279. https://doi.org/ $10.3390 /$ ijms 22126279

Academic Editors: Soraya L. Valles and Nitin Saksena

Received: 20 April 2021

Accepted: 8 June 2021

Published: 11 June 2021

Publisher's Note: MDPI stays neutral with regard to jurisdictional claims in published maps and institutional affiliations.

Copyright: (C) 2021 by the authors Licensee MDPI, Basel, Switzerland. This article is an open access article distributed under the terms and conditions of the Creative Commons Attribution (CC BY) license (https:// creativecommons.org/licenses/by/ $4.0 /)$.
Abstract: Herpes simplex virus 1 (HSV-1) is a widespread neurotropic virus establishing a life-long latent infection in neurons with periodic reactivations. Recent studies linked HSV-1 to neurodegenerative processes related to age-related disorders such as Alzheimer's disease. Here, we explored whether recurrent HSV-1 infection might accelerate aging in neurons, focusing on peculiar marks of aged cells, such as the increase in histone H4 lysine (K) 16 acetylation (ac) (H4K16ac); the decrease of $\mathrm{H} 3 \mathrm{~K} 56 \mathrm{ac}$, and the modified expression of Sin3/HDAC1 and HIRA proteins. By exploiting both in vitro and in vivo models of recurrent HSV-1 infection, we found a significant increase in H4K16ac, Sin3, and HDAC1 levels, suggesting that the neuronal response to virus latency and reactivation includes the upregulation of these aging markers. On the contrary, we found a significant decrease in H3K56ac that was specifically linked to viral reactivation and apparently not related to aging-related markers. A complex modulation of HIRA expression and localization was found in the brain from HSV-1 infected mice suggesting a specific role of this protein in viral latency and reactivation. Overall, our results pointed out novel molecular mechanisms through which recurrent HSV-1 infection may affect neuronal aging, likely contributing to neurodegeneration.

Keywords: HSV-1; Herpes simplex virus; recurrent infection; neuronal aging; histone modifications

\section{Introduction}

HSV-1 is a neurotropic virus able to establish a life-long infection in neurons. After a primary infection in the epithelial cells, the virus contacts the axonal endings of sensory and sympathetic neurons in the site of primary infection [1,2] and, via retrograde axonal transport, reaches the cell bodies in the ganglia of the peripheral nervous system (PNS) where it establishes a latent infection. In this condition, viral replication is blocked, and viral genome remains in the episomal form in the nuclei of infected neurons. Throughout the host's life, the virus may reactivate as a result of several stimuli, including exposure to UV-light, stress, fever, and immune suppression [2]. Successful reactivation allows the production of new viral particles that, traveling along the axon, return to the primary infection site (e.g., oral mucosal epithelial cells) and give rise to recurrent infection (symptomatic or asymptomatic). More rarely, these viral particles may also reach the central nervous system (CNS) where they can infect neurons causing a severe herpetic encephalitis or, likely, establishing a latent infection [1,3-5]. An increasing body of data pointed out herpesviruses infections, such as HSV-1, as co-risk factors in the CNS neurodegenerative diseases, including Alzheimer's disease (AD), the main form of dementia in the elderly [1,6-15]. In this 
context, recent data from our group demonstrated that recurrent HSV-1 infection causes the accumulation of AD hallmarks in mice, including amyloid beta peptides $(\mathrm{A} \beta \mathrm{s})$ and hyperphosphorylated tau, as well as signs of neuroinflammation and irreversible cognitive deficits [3]. Specifically, we observed a correlation between the number of viral reactivations and the progressive accumulation of these markers in HSV-1-infected mice compared to control ones.

Aging is considered one of the main risk factors for several neurodegenerative disorders, including AD [16,17]. Consistently, some of the major AD players are strictly associated to aging markers; for instance, $\mathrm{A} \beta$ oligomers are reported to induce a senescent phenotype in neural stem cells (NSCs), including enlarged and flattened morphology, increased levels of senescence-associated $\beta$-galactosidase (SA- $\beta$-gal) and activation of cyclin-dependent inhibitor $\mathrm{p} 16^{\mathrm{INK} 4}$. These signs have been also identified in both aged cells [18] and AD cortical brain tissues [19-24]. Intriguingly, aging may also affect the chromatin landscape: several factors and their post-transcriptional modifications (PTMs) have been indeed pointed out as aging markers, including the acetylation levels of two specific residues of histone $\mathrm{H} 3$ and H4, lysine 56 (K56) and lysine 16 (K16) (H3K56ac and H4K16ac). Specifically, a decrease in H3K56ac during replicative senescence was reported, suggesting a role for this PTM in lifespan regulation [21,25]. On the contrary, the acetylation of H4K16 was reported to increase with age, and H4K16ac was found enriched at promoter regions of genes expressed in senescent cells independently of their expression [25-27]. The acetylation level of these lysine residues is regulated by the class I histone deacetylases (HDACs) family, which are enzymes involved in transcription and gene repression [28]. For instance, HDAC1 is recruited by several chromatin regulator complexes, such as CoREST/LSD1/REST and Sin3/HDAC1 co-repressor complex [29], two complexes that exert a role in the regulation of HSV-1 replication, repressing viral gene expression. Interestingly, HDAC1 aberrant activity has been linked to neurodegeneration and its export to the cytoplasm promotes axonal and neuronal degeneration in different pathological conditions [30,31]. Moreover, HDAC1 expression increases with aging in the human brain, potentially leading to a neurotoxic effect and, ultimately, to neuronal death [30,32].

The histone regulator A (HIRA) chaperone, involved in DNA synthesis-independent nucleosome assembly through the incorporation of H3.3 histone variant [33], is another crucial player in aging. In aged cells, HIRA participates to the formation of the senescenceassociated heterochromatic foci (SAHFs) [34,35] and HIRA complex colocalizes with the tumor suppressor promyelocytic leukemia (PML) protein in PML-nuclear bodies (PMLNBs) [36,37], whose formation depends on cellular stress such as DNA-damage, and oxidative stress. It is noteworthy that HIRA, together with PML, works as a restriction factor for DNA viruses, including HSV-1, e.g., it activates innate cell responses (including Interferon stimulated gene expression) and contributes to viral gene silencing to limit virus replication [38-41].

In the last few years, many pieces of evidence linked aging to persistent viral infections, including that caused by human immunodeficiency (HIV) and hepatitis $\mathrm{C}$ viruses (HCV) [42-44] and very recently HSV-1 [45]. Regarding HSV-1, notwithstanding the amount of data on the mechanisms regulating its latency and reactivation in neurons, the long-term effects of recurrent infection on aging are poorly characterized, and the possibility that this infection may also impair and accelerate the normal neuronal aging remains unexplored thus far. Thus, in the present study, we investigated the influence of HSV-1 infections on the host age-related chromatin balance in neurons by evaluating changes in the levels of peculiar markers of aging and associated factors. We exploited both in vitro and in vivo models of recurrent HSV-1 infection in order to study the effect of infection in neurons and its progresses during aging and multiple reactivations [3,46]. We found: (i) an HSV-1-reactivation-dependent decrease of H3K56ac; (ii) an H4K16ac increase and a significant increase of Sin3 and HDAC1 protein persistent within the recurrent HSV-1 infection; (iii) a significant increase in HIRA protein levels during viral latency and its 
different localization in cortical neurons from HSV-1 infected mouse brains. Overall, our data highlight an additional mechanism through which recurrent HSV-1 infection causes long-term alterations in neurons, thus contributing to neurodegeneration.

\section{Results}

2.1. H3K56 and H4K16 Acetylation Levels Are Inversely Modulated by Recurrent HSV-1 Infection in Neurons

To investigate whether recurrent HSV-1 infection may accelerate the normal neuronal aging, we first set up an in vitro model of HSV-1 infection and reactivation in cultures of rat primary neurons as previously described [46] with minor modifications. Briefly, day in vitro 7 (DIV7) primary neurons were inoculated with 0.1 multiplicity of infection (M.O.I.) of HSV-1 or Mock solution (hereafter named HSV-1 and CTRL, respectively) and harvested 24 hours (h) post-infection (p.i.) or $24 \mathrm{~h}$ post-viral reactivation (p.r.). The latter group of neurons was treated with $50 \mu \mathrm{M}$ acycloguanosine (ACV) starting from $18 \mathrm{~h}$ before the virus or mock inoculation (Figure 1a) to allow the establishment of latent infection; 10 days postinfection (d.p.i.), neurons were subjected to thermal stress (TS; $10 \mathrm{~min}, 42^{\circ} \mathrm{C}$ ) in the absence of ACV to induce HSV-1 reactivation, as described in Materials and Methods. Neuronal aging markers were studied at two experimental time points, resembling two faces of HSV1 infection in neurons: (i) $24 \mathrm{~h}$ p.i. (i.e., when the virus has completed its life-cycle following the primary infection), to study the effects of the virus after the acute infection; (ii) $24 \mathrm{~h}$ p.r. (i.e., when it has completed a cycle of latency and reactivation), to study the effects of the virus long-lasting infection following a reactivation cycle after 10 days of latency. Latency establishment, as well as the efficacy of virus infection and reactivation, were assessed by Standard Plaque Assay (SPA) (Figure 1b or In Cell Western (ICW) assay in Supplementary Figure S1). To assess if acute or recurrent HSV-1 infections could accelerate aging of neurons we focused our investigation on the two lysine residues, H4K16 and H3K56, whose acetylation was reported to be modulated during aging. In particular, it is known that the acetylation levels of H3K56 decrease during aging in various organisms [25,47], whereas those of H4K16 increase [26,27]. Results from Western Blotting (WB) analyses of acetylation levels show a trend increase in H4K16 acetylation (H4K16ac) after primary infection compared to Mock-infected neurons, which was maintained 24 h p.r. (Figure 1c). On the contrary, the acetylation of H3K56, which did not show any alteration $24 \mathrm{~h}$ p.i., was significantly reduced after 1 cycle of latency and reactivation in HSV-1-infected neurons with respect to matched controls, $\left({ }^{*} p<0.05\right)$ (Figure $\left.1 c\right)$, likely indicating that the virus is able to affect the acetylated status of this lysine residue within a long-lasting infection. Overall, these data suggest that recurrent HSV-1 infection could affect the acetylation of these amino acidic residues, especially for H3K56.

a

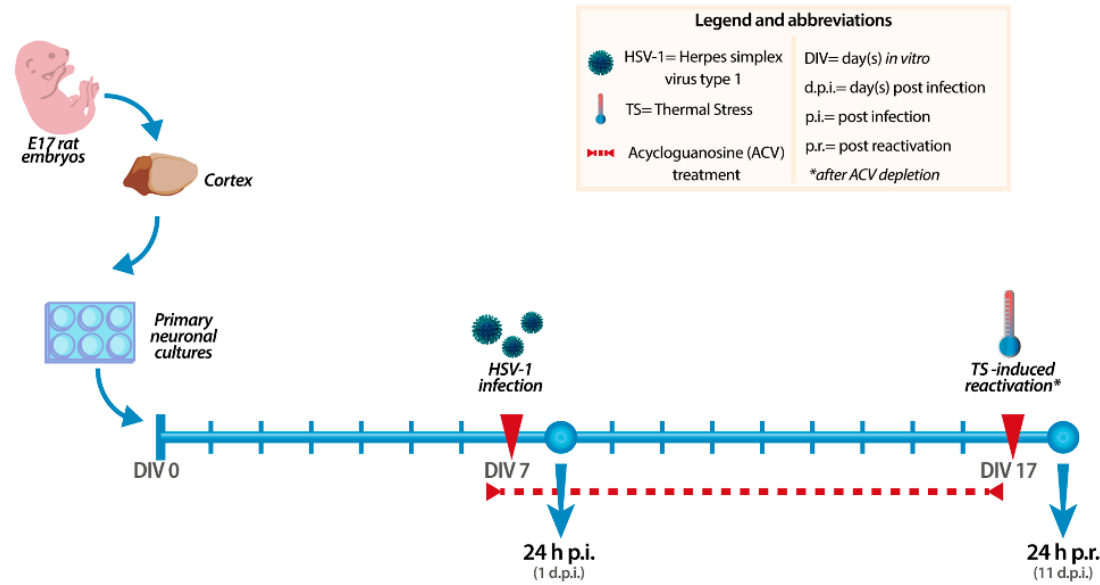

Figure 1. Cont. 
b

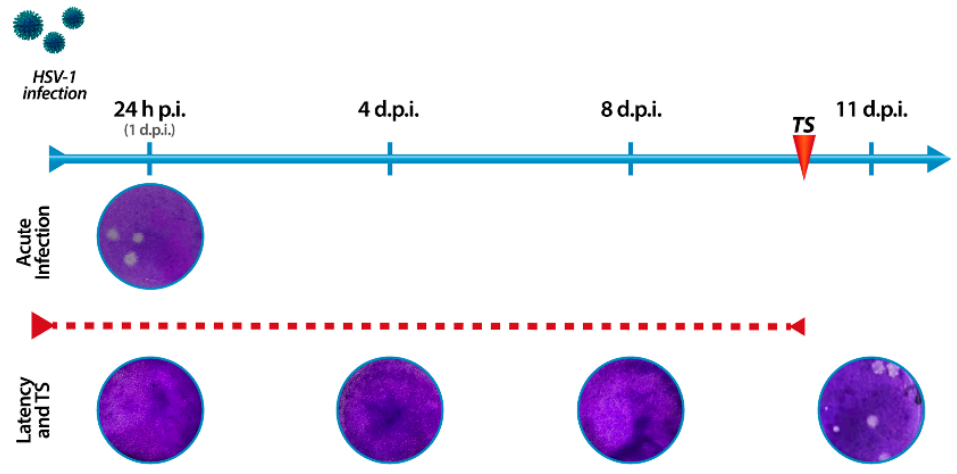

c
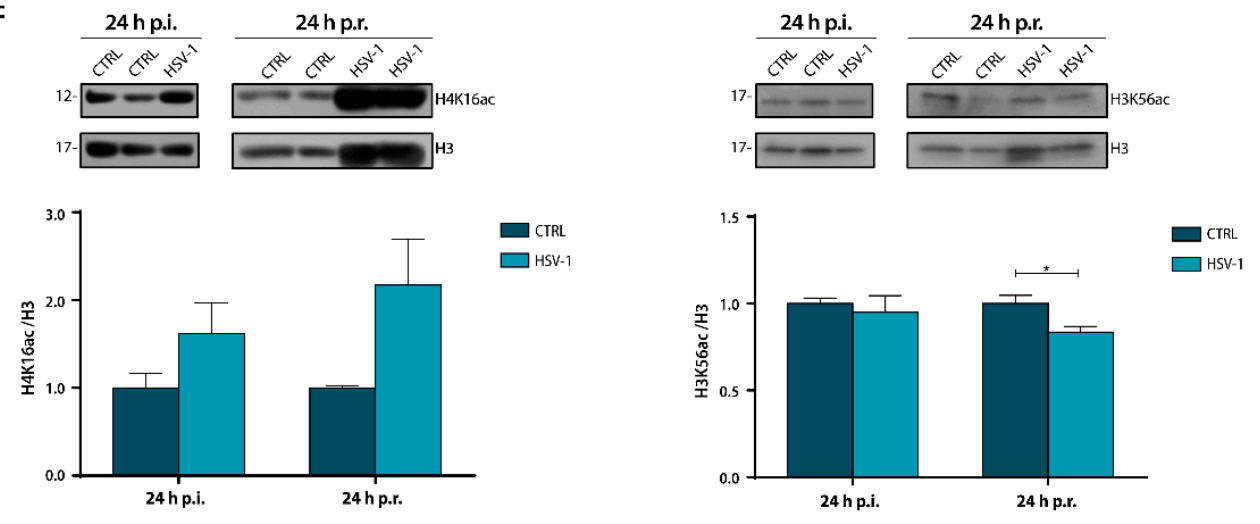

Figure 1. In vitro experimental model and histones acetylation levels during a recurrent HSV-1 infection in neurons. (a) Timeline of experimental procedures showing the days in culture of the neurons, the ACV treatment (red dashed line), the time of primary infection (DIV 7) and reactivation (DIV 17), and the time points chosen for the analyses: $24 \mathrm{~h}$ p.i. (DIV 8) and $24 \mathrm{~h}$ p.r. (DIV18). Abbreviations are shown in the yellow box. (b) Representative images of standard plaque assay (SPA) after primary infection (24 h p.i.) with or without ACV (Acute Infection and Latency and TS rows, respectively), during ACV-induced latency (4 and 8 d.p.i.) or after TS-induced reactivation (11 d.p.i.). (c) Representative immunoblots showing H4K16 and H3K56 acetylation levels in lysates from Mock- and HSV-1-infected neuronal cultures harvested 24 h p.i. or 24 h p.r.. H3 staining was used as a loading control. Densitometric analyses were performed with Quantity One software and normalized to $\mathrm{H} 3$ expression. The values represent the normalized fold-changes in acetylation levels from HSV-1 samples with respect to matched CTRL. Data are mean \pm SEM. ${ }^{*} p<0.05$. Statistical significance was calculated by the Mann-Whitney test.

\subsection{Sin3 and HDAC1 Protein Levels Increase during In Vitro Recurrent HSV-1 Infection}

To gain insight into the decrease in $\mathrm{H} 3 \mathrm{~K} 56 \mathrm{ac}$, we investigated whether HSV-1 infection and reactivation could affect the expression levels of the components of the repressor complex Sin3a/HDAC1, known to be involved in histone deacetylation. Results showed a significant increase in Sin3 and HDAC1 levels in HSV-1 infected neurons 24 h p.r. with respect to matched CTRL, whereas no significant changes were detected $24 \mathrm{~h}$ after the primary infection (Figure 2a,b; 24 h p.r.: Sin3, ${ }^{*} p=0.017$ vs. CTRL; HDAC1, ${ }^{*} p=0.035$ vs. CTRL). These results were congruent with the decrease found in H3K56ac level suggesting that recurrent HSV-1 infection, and not primary infection, by affecting these protein levels, may modulate the histone acetylation ones. However, we also observed a time-dependent increase in the expression levels of both proteins, probably due to the HSV-1 latent and long-term infection. 

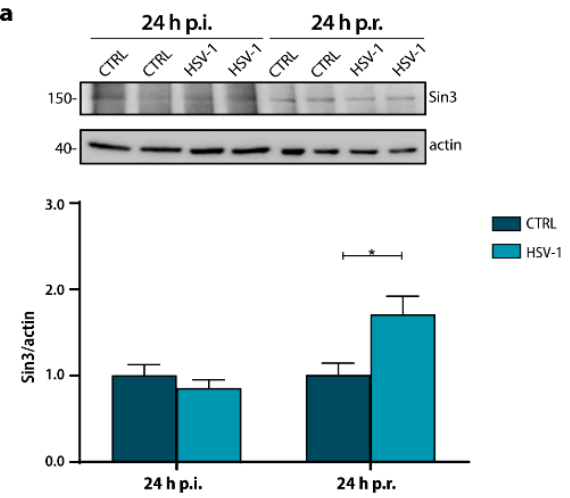

c
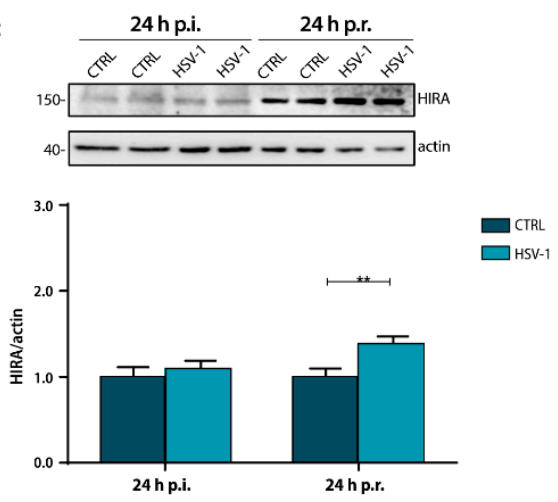

b
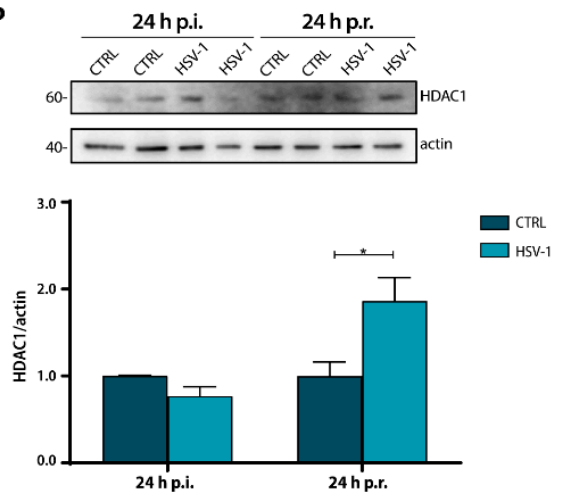

Figure 2. Sin3, HDAC1 and HIRA expression during a recurrent HSV-1 infection in vitro. Representative immunoblots showing Sin3 (a), HDAC1 (b), and HIRA (c) protein levels in lysates from Mockand HSV-1-infected neuronal cultures harvested $24 \mathrm{~h}$ p.i. or $24 \mathrm{~h}$ p.r. Actin staining was used as a loading control. Densitometric analyses were performed with ImageLab software and normalized to actin expression. The values represent the normalized fold-changes in protein levels from $24 \mathrm{~h}$ p.r. CTRL or HSV-1 samples with respect to $24 \mathrm{~h}$ p.i. CTRL. Data are mean \pm SEM of three independent experiments. ${ }^{*} p<0.05 ;{ }^{* *} p<0.01$. Statistical significance was calculated by Mann-Whitney test.

\subsection{Recurrent HSV-1 Infection Induces HIRA Increase in 24 h p.r. Neurons}

Next, we investigated the expression levels of the senescence-associated HIRA protein. This key senescence-regulator factor was required for the formation of SAHF during cell aging. Recently, the role of HIRA in the establishment of HSV-1 latency in the PML-NB has been demonstrated [48]. Thus, we analyzed HIRA expression levels in primary neuronal culture harvested $24 \mathrm{~h}$ p.i. or $24 \mathrm{~h}$ p.r. Figure 2c shows a significant increment of HIRA following virus reactivation $(* * p=0.009)$. On the contrary, no significant increase on the protein expression was observed after primary infection ( $24 \mathrm{~h}$ p.i.). First, as expected, we noticed that HIRA levels increased in control neurons within the days in culture, indicating the aging of neuronal cultures). Moreover, we observed a significant increment in HIRA during long-lasting infection $\left(24\right.$ h p.r.) $\left.{ }^{* * * *} p<0.0001\right)$. These results indicate that HSV-1 significantly increased HIRA protein level in the long-term infection.

\subsection{Recurrent HSV-1 Infection Modifies Histone Acetylation Profile and Sin3/HDAC1 Protein Levels in Mice}

Since aging involves many mechanisms that could be minimized in a simple model as a cell culture, we deepened our study in vivo, by exploiting a mouse model of recurrent HSV-1 infection set up in our lab, that was previously virologically and molecularly characterized [3]. Specifically, we decided to analyze brain tissues from subgroups of mice (Figure 3a) sacrificed at different stages of HSV-1 infection or Mock-infection: (i) a subgroup of HSV-1-infected mice (HSV1-M) and Mock-infected mice (CTRL-M) was sacrificed 4 days after infection, during the acute phase of primary infection (i.e., when the virus was still 
actively replicating, and it have reached several brain areas as previously documented [3]). These mice were named hereafter HSV1-M and CTRL-M 4 d.p.i.; (ii) two subgroups of mice underwent several TS-inducing viral reactivation over life and were sacrificed following the 3rd TS (at 6 months of age, named hereafter Post 3TS) or the 7th TS (13 months of age, named hereafter Post 7TS), i.e., when the virus was actively replicating in the brain; (iii) a subgroup of mice underwent 6 TSs and was sacrificed $24 \mathrm{~h}$ just before the 7th TS (named hereafter Pre 7TS), that was when the virus was dormant in the brain, after 6 cycles of virus reactivation.

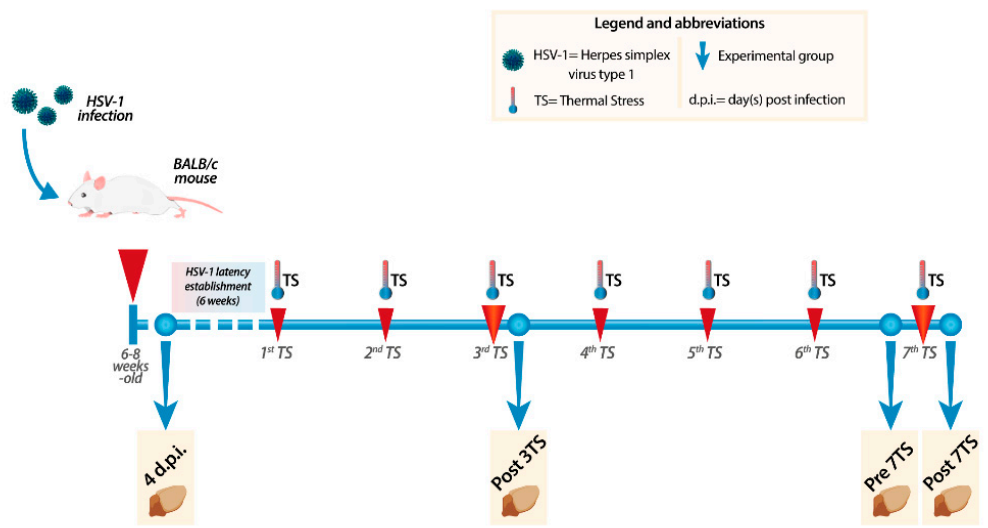

b
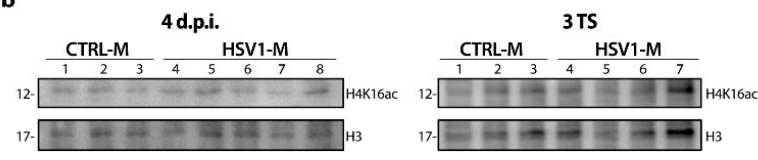

Pre 7TS Post 7TS
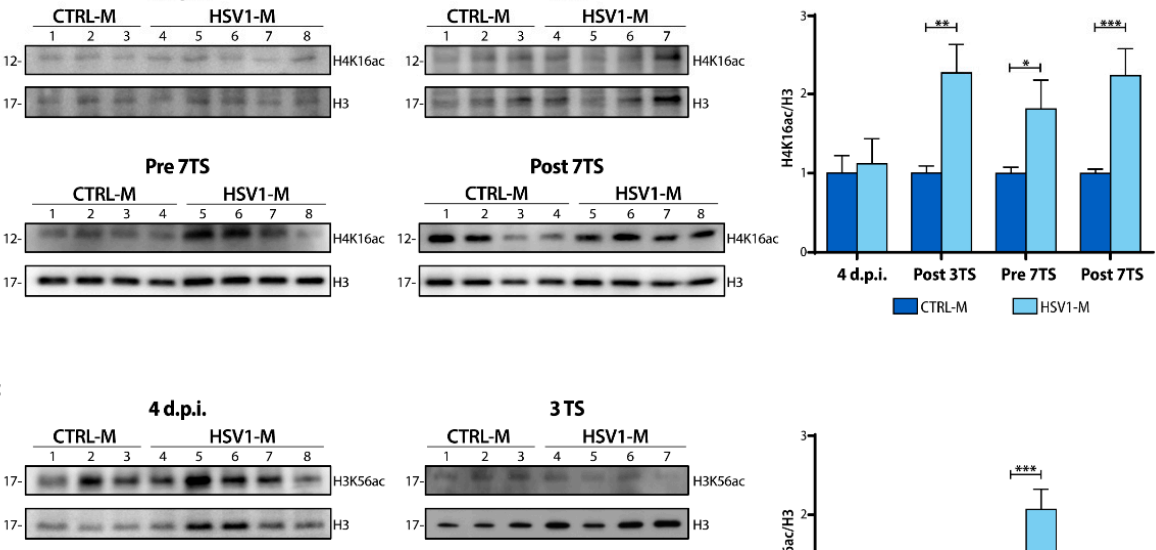

Pre 7TS
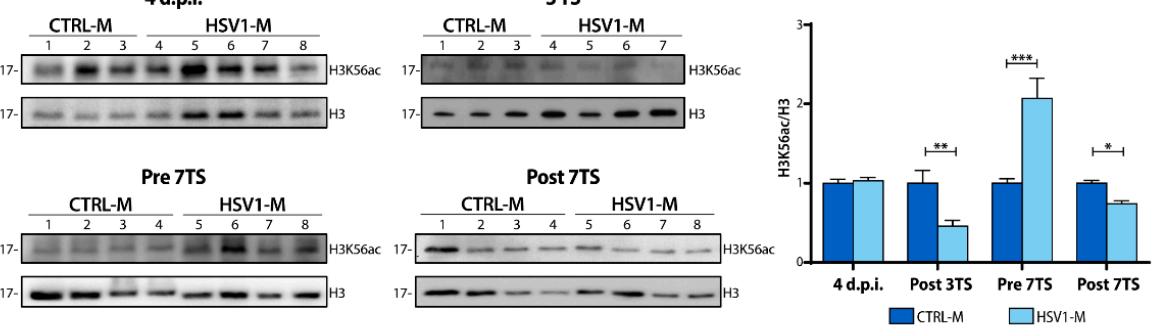

Figure 3. Schematic representation of the recurrent HSV-1 infection and modulation of histone acetylation levels in vivo. (a) Timeline showing HSV-1 infection, TS-induced virus reactivations, and chosen experimental time-points over the mouse life. The HSV-1 inoculation (primary infection) was performed by snout abrasion (first red arrow). TS induces viral reactivations are indicated by red arrows. The dashed line indicates the establishment of the latent infection. Mice were sacrificed and analyzed at the following time points (blue dots) indicated by the yellow boxes: 4 d.p.i., following the 3rd (at 6 months of age, Post 3TS) and the 7th TS (13 months of age, Post 7TS) or $24 \mathrm{~h}$ just before the 7th TS (Pre 7TS). Representative WBs showing H4K16 (b) and H3K56 (c) acetylation levels in the whole lysate from the cortices of 4 d.p.i., Post 3TS, Pre and Post 7TS mice. Densitometric analyses were performed with ImageLab software and normalized to $\mathrm{H} 3$ or tubulin expression. The values represent the normalized fold-changes in protein levels from HSV1-M with respect to CTRL-M. Data are mean \pm SEM. ${ }^{*} p<0.05 ;{ }^{* *} p<0.01 ;{ }^{* * *} p<0.001$. Statistical significance was calculated by multiple t-test and determined using the Sidak-Bonferroni method, with alpha $=0.05$. 
Firstly, we checked whether multiple cycles of viral latency and reactivation as well as primary virus infection could affect the H4K16 and H3K56 acetylation patterns in mouse brains by WB analysis of cortical homogenates from Post 3TS, Pre 7TS, Post 7TS mice, and 4 d.p.i. mice. We found that TS-induced viral replications caused a significant increase in histone H4K16 acetylation (Figure $3 b$ ) (Post 3TS: ${ }^{* *} p=0.001$ vs. CTRL-M; Post 7TS: $* * * p=0.001$ vs. CTRL-M). We also detected a high level in acetylation in Pre 7TS mice, indicating that this trend was maintained within recurrent virus infection in the brain ( ${ }^{*} p=0.03$ vs. CTRL-M). On the contrary, we found no significant changes in 4 d.p.i. mice, in line with the data obtained with the in vitro model of HSV-1 infection following the primary infection.

Regarding the lysine 56 acetylation, we detected a significant decrease in H3K56ac levels in HSV1-M compared to those observed in CTRL-M (Figure 3c) $24 \mathrm{~h}$ after both the 3rd and 7th TSs, suggesting again a possible long-lasting effect of the viral infection on the acetylation of this residue (Post 3TS: ${ }^{* *} p=0.002$ vs. CTRL-M; Post 7TS: ${ }^{*} p=0.033$ vs. CTRL-M). Unexpectedly, the H3K56ac levels were significantly higher in Pre 7TS HSV1-M with respect to matched CTRL- M and to those of Post 7TS HSV1-M (Figure 3c, bar graphs Pre 7TS; *** $p<0.0001$ vs. CTRL-M).

Then, to verify if multiple cycles of viral latency and reactivation could also affect Sin 3 and HDAC1 levels, we investigated their protein levels in mouse cortices. We found a significant increase in Sin3 and HDAC1 protein expression levels in 4 d.p.i. HSV1-M with respect to CTRL-M (Figure 4a; 4 d.p.i.: Sin3, ${ }^{*} p=0.010$ vs. CTRL-M; Figure $4 \mathrm{~b}$, HDAC1, ${ }^{*} p=0.046$ vs. CTRL-M). Moreover, this trend was observed also after multiple viral reactivations (Figure 4a; Post 7TS Sin $3,{ }^{* * *} p<0.001$ vs. CTRL-M; Figure 4b, HDAC1, ** $p=0.008$ vs. CTRL-M). The most consistent increase in Sin3/HDAC1 levels was found in Pre 7TS mice, i.e., when the virus was in the latent phase, compared to matched controls (Pre 7TS: Sin $3,{ }^{* * *} p<0.0001$ vs. CTRL-M; HDAC1, ${ }^{* *} p=0.006$ vs. CTRL-M). Indeed, the levels of both $\operatorname{Sin} 3$ and HDAC1 were markedly higher than those found in mice subjected to TS-induced reactivation. These results confirm the Sin 3 and HDAC1 expression observed in vitro, picturing a complex virus-host cell relationship throughout host life/time.

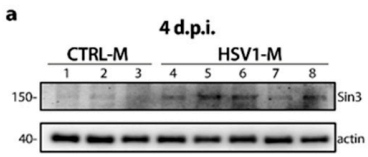

Pre 7TS

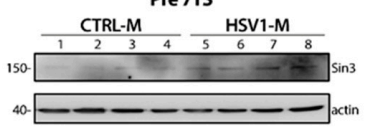

b

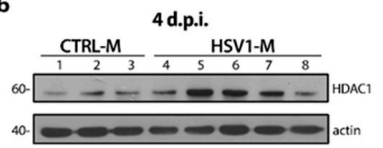

Pre $7 T S$

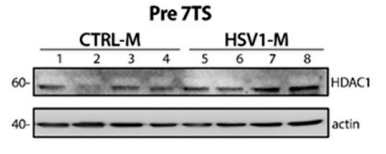

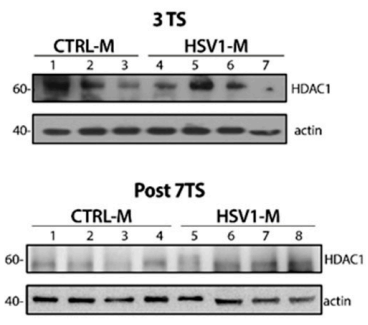
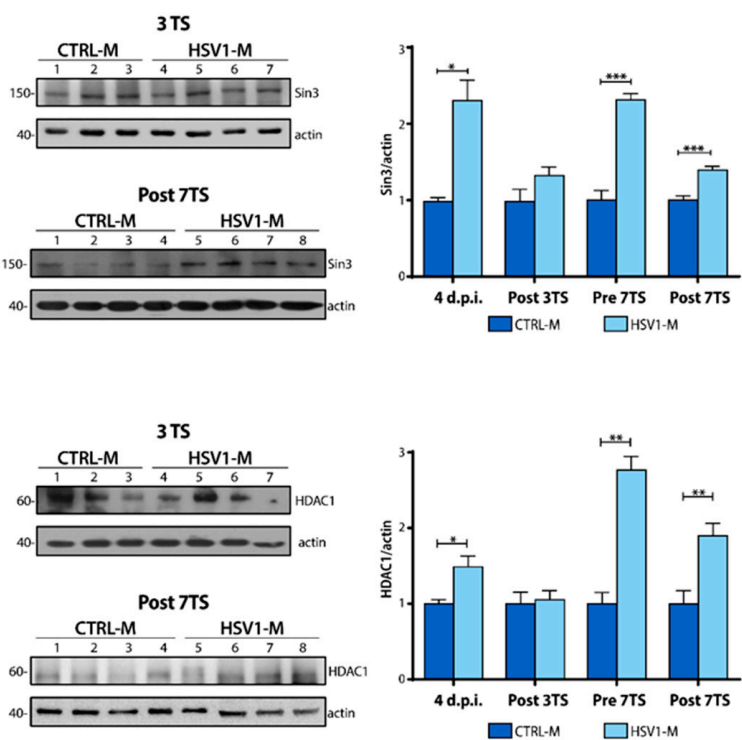

Figure 4. Recurrent HSV-1 infection induces an increase in Sin3 and HDAC1 protein expression. Representative WBs showing Sin3 (a) and HDAC1 (b) protein levels in the whole lysate from the cortices of 4 d.p.i., Post 3TS, Pre and Post 7TS mice. Densitometric analyses were performed with ImageLab software and normalized to $\mathrm{H} 3$ or tubulin expression. The values represent the normalized fold-changes in protein levels from HSV1-M with respect to CTRL-M. Data are mean \pm SEM. ${ }^{*} p<0.05 ;{ }^{* *} p<0.01$; ${ }^{* * *} p<0.001$. Statistical significance was calculated by multiple $t$-tests and determined using the Sidak-Bonferroni method, with alpha $=0.05$. 


\subsection{Recurrent HSV-1 Infection Induces HIRA Increase during Viral Latency in Mice}

Next, we checked whether modulation of HIRA expression occurred also during the recurrent HSV-1 infection in our mouse model. In marked contrast to what we found in $24 \mathrm{~h}$ p.r. neurons, results showed a drastic reduction (up to 50\%) in HIRA protein amounts following the 3rd TS in HSV1-M with respect to matched controls (Figure 5; bar plot; Post 3TS: ${ }^{* * *} p<0.0001$ vs. CTRL-M). A lower trend of decrease was also found in HSV-1-infected Post 7TS mice, suggesting an effect of viral reactivation on the protein half-life in mouse cortex. On the contrary, we detected a notable increase of HIRA levels in Pre 7TS HSV1-M, as shown in Figure 5 (bar graph; Pre 7TS: $* * * p=0.0004$ vs. CTRL$\mathrm{M})$. These levels were significantly higher than those found in both Post 3TS and Post 7TS HSV-1-infected mice. This result suggests that, after several cycles of TS, HIRA is more produced or preserved, and accumulates in cortical neurons during the viral latency. Consistently, the slight HIRA modulation found in HSV1-M Post 7TS may result from a balance between the aging-dependent accumulation of HIRA and the HSV-1-induced downregulation. Notably, no differences were observed 4 d.p.i. This probably depends on the number of neurons infected after only 4 days from primary infection and the total amount of HIRA in 6-8 weeks-old mice.
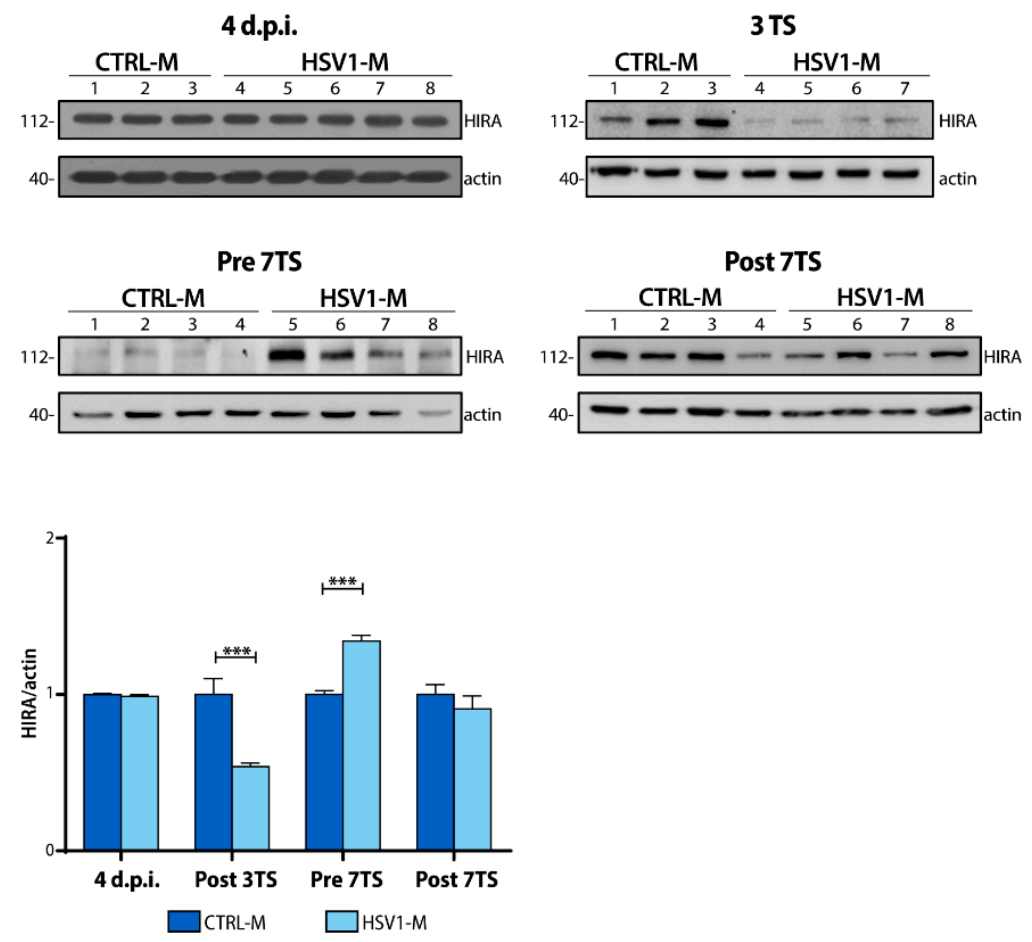

Figure 5. HIRA protein expression in the cortex of recurrent HSV-1 infection mouse model. Representative WBs of HIRA protein expression 4 d.p.i., $24 \mathrm{~h}$ after the 3rd and the 7th TS (Post 3TS and Post 7TS respectively), or $24 \mathrm{~h}$ before the 7th TS (Pre 7TS). Densitometric analyses were performed with ImageLab software and normalized to actin expression level. The values represent the normalized fold-changes in protein levels from HSV1-M with respect to CTRL-M (bar graph on the left). Data are mean \pm SEM. ${ }^{* * *} p<0.001$. Statistical significance was calculated by multiple t-tests and determined using the Sidak-Bonferroni method (bar graph, alpha $=0.05$ ).

To gain insight into these results, we carried out confocal immunofluorescence analyses (IF) of mouse brain slices to investigate the localization of HIRA protein (Figure 6). IF staining was performed on brain slices obtained from CTRL-M and HSV1-M sacrificed $24 \mathrm{~h}$ before or after the 7th TS with a specific anti-HIRA protein antibody (green). Slices were also stained with anti-NeuN antibody (red) to mark nuclei and perinuclear cytoplasm of neurons, and diamidino-2-phenylindole (DAPI, blue) to stain all cellular nuclei. Confocal IF analysis confirmed the trend we previously observed in WB. Specifically, the mean 
fluorescence intensity of neuronal HIRA protein (i.e., detected in $\mathrm{NeuN}^{+}$cells) was found to be significantly increased in Pre 7TS HSV1-M with respect to age-matched control mice (Figure 6; Pre 7TS ** $p=0.004$ vs. CTRL-M). Moreover, HIRA seems to be affected by virus reactivation as its intensity was found slightly decreased in Post 7TS HSV1-M tested compared to Pre 7TS mice, although it was significantly higher with respect to matched CTRL-M (Figure 6; Post 7TS $*=0.02$ vs. CTRL-M). Furthermore, the nuclear localization of the protein changed in the infected Pre 7TS where HIRA was distributed perinuclearly in a more extensive way, contrary to CTRL-M, where HIRA was localized in more compact foci. Similarly, this occurred also in the Post 7TS, although the quantity of the protein decreased after reactivation.
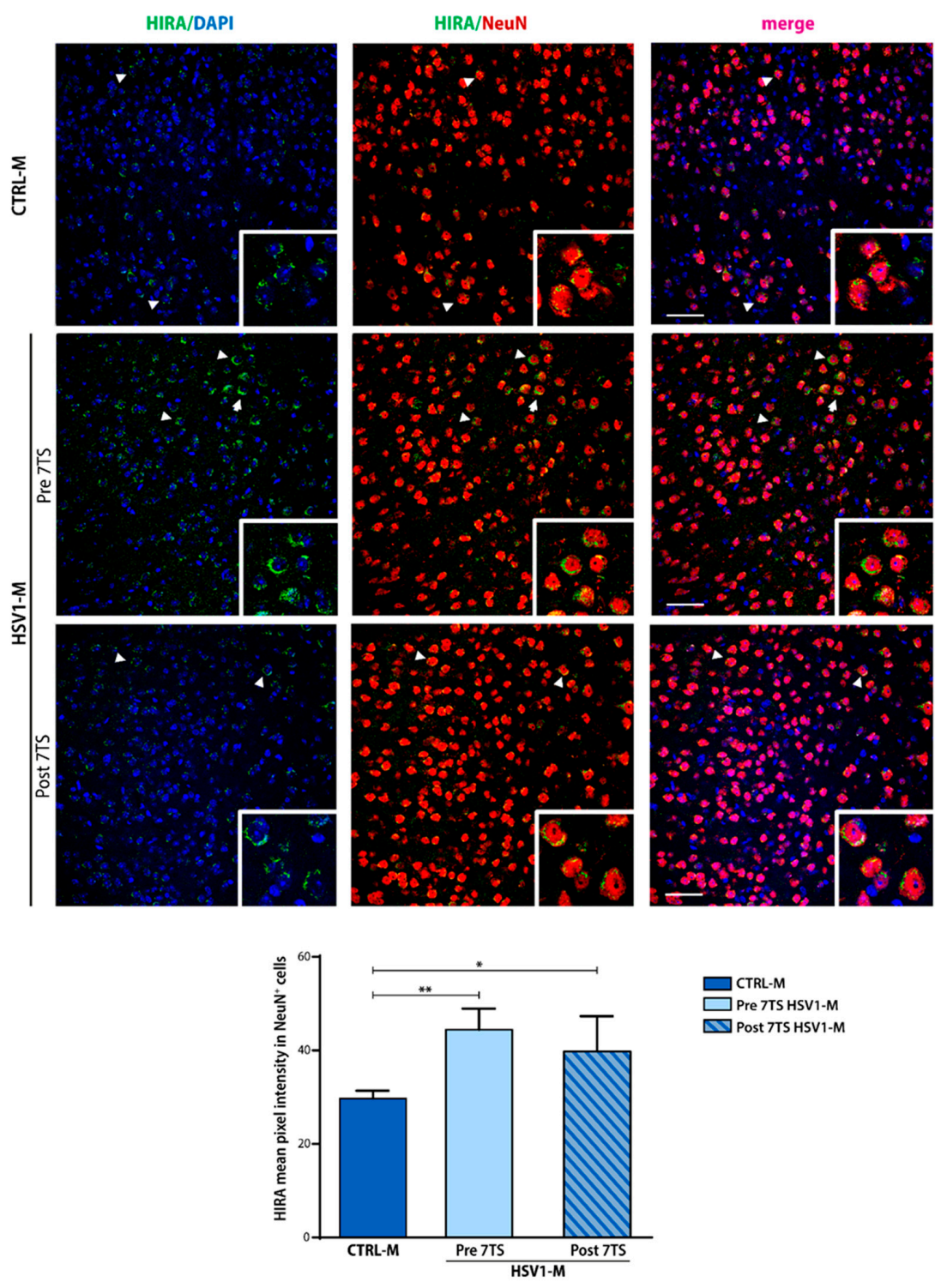

Figure 6. Cortical HIRA intensity changes during the recurrent HSV-1 infection. Confocal immunofluorescence analysis showing the immunostaining for NeuN (red) and HIRA (green) in coronal brain slices from HSV-1- or Mock-infected mice (HSV1-M and CTRL-M, respectively) sacrificed before or after the 7th TS (13 months of age). Cellular nuclei are stained by DAPI (blue). The insets represent the enlargement of HIRA-positive neurons pointed by white arrowheads (10× magnification). Bar graphs show the HIRA mean pixel intensity quantified in NeuN-positive cells ( $\mathrm{NeuN}^{+}$, i.e., neurons). Two coronal sections were analyzed for each brain. ${ }^{*} p<0.05 ;{ }^{* *} p<0.01$. Statistical significance was calculated by multiple t-tests and determined using the Sidak-Bonferroni method (bar graph, alpha $=0.05)$. Scale bar: $50 \mu \mathrm{m}$. 
Altogether these data indicate that HIRA is stable during viral latency, probably aiding the viral DNA repression, whereas TS-induced HSV-1 reactivation modifies the protein stability inducing its degradation and/or delocalization from the nucleus, similarly to other repressive factors (e.g., PML).

\section{Discussion}

In the present study, we addressed the hypothesis that recurrent HSV-1 infection may accelerate brain aging. To our knowledge, very few pieces of information are currently available about the appearance of aging markers and modulation of aging-related factors within recurrent HSV-1 infection. Previous studies of our group demonstrated that multiple HSV-1 reactivations in wild-type mice lead to the accumulation of neurodegenerative hallmarks and cognitive deficits typical of AD brain [3]. In this study, we exploited this experimental model and set up a compatible in vitro model of recurrent HSV-1 infection (i.e., HSV-1 infection followed by the establishment of a 10-day latency and, then, by TSinduced reactivation). Our results showed that both in vitro and in vivo recurrent HSV-1 infection modulate histone acetylation levels of two lysine residues (K16 of H4 and K56 of $\mathrm{H} 3$ ) that have been related to the aging process in several organisms. The same residues are known to be modified during acute HSV-1 infection in vitro [25,26,49-51]. In our study, we found that HSV-1 induced a significant increase in H4K16ac after multiple reactivations in vivo (Figure $3 b$ ), while a slight but reproducible increase was observed following a single reactivation in vitro (Figure 1c). Interestingly, H4K16ac increment was also found during viral latency in Pre 7TS mice, suggesting that recurrent HSV-1 infection may induce the persistence of higher H4K16ac levels, which is indicative of accelerated aging. Indeed, O'Sullivan (2010) reported that the increase in H4K16ac is an aging-related chromatin marker and regulates the chromatin state. Our data are in line also with those reported by Nativio et al. (2018), which showed H4K16ac increased in aged human brain samples (postmortem) with respect to control of young brain samples [26]. On the contrary, Contrepois et al. (2012) reported a decrease in H4K16 acetylation during replicative senescence. This discrepancy may be due to the use of different experimental models: Contrepois et al. exploited human embryonic fibroblasts forced to replicative senescence via overexpression of RAF skipping the DNA damage checkpoint activation [52], whereas our data were obtained in primary wild type neurons (i.e., post-mitotic cells that undergone senescencelike phenotype) and mouse cortices from HSV-1 infected wild-type mice. Although similar pathways are involved, it is also reasonable to hypothesize that the oncogene-induced-and virus-induced-senescence may drive different effects on H4K16 residue. Moreover, it is possible that the increase of H4K16ac may be related to other factors, including the agerelated decrease of Sirt1, one of the histone deacetylases responsible for this modification, which is also known to be modulated during HSV-1 infection [53,54].

Regarding H3K56 acetylation level, whose decrement was documented both in yeast and human cell cultures during replicative senescence [25,47], we found that it is not affected in HSV-1 acute infection (both in vitro and in vivo), whereas a decrease in this PTM was observed in neurons $24 \mathrm{~h}$ after virus reactivation from latency (Figure 1c) as well as in the mouse model of recurrent HSV-1 infection (Figure 3c). We also detected a significant H3K56ac increase in those mice analyzed before the 7th TS. Taken together, these results suggest that $\mathrm{H} 3 \mathrm{~K} 56$ deacetylation may be triggered by the productive infection that follows virus reactivation, whereas other mechanisms may be activated within the viral latency. Therefore, we argued that this modification might not correlate with aging under our experimental conditions. Interestingly, Miller and colleagues showed that H3K56 deacetylation is also a downstream DNA damage responsive PTM carried out by HDAC1, and our and other groups previously demonstrated that HSV-1 induces DNA damage during productive infection $[28,55]$. Hence, it is possible to speculate that the detected H3K56ac decrease is a DNA-damage indicator. Further studies are required to clarify where these markers are positioned in the chromatin landscape. 
HDAC1 and Sin 3 are involved in many cellular processes, including the antiviral response. Gilbert et al. showed that HDAC1 increased in human postmortem brains in an age-dependent manner, and Sin 3 has also been associated with senescence [32,56]. In our models, we found that both Sin 3 and HDAC1 protein levels raised during the recurrent HSV-1 infection (Figure 2a,b, and Figure 4) with respect to matched controls, supporting the view that multiple HSV-1 reactivations may accelerate brain aging. The increase of these protein levels was also detected during latency (in vivo, pre7TS) and may be linked to the repression of the viral genome in the PML-NB. However, we found different results in in vitro ( $24 \mathrm{~h}$ p.i.) and in vivo (4 d.p.i. mice) models of primary infection on $\operatorname{Sin} 3$ and HDAC1 levels. It is possible that HSV-1-induced Sin3/HDAC1 increase in vivo may be related to inflammatory response due to viral infection, whereas in vitro neurons lacking their immune-related counterpart (glial cells) did not show this mechanism.

Next, we focused our attention on HIRA protein expression and localization. HIRA complex colocalizes with the PML-NBs in senescent cells, and during HSV-1 latent infection, HIRA is involved in the repression of the viral genome. Recently, Rai et al. demonstrated that H4K16ac is enhanced on the promoters of expressed genes in senescent cells, and its enrichment is preserved by HIRA protein [57]. Our in vitro results showed that HIRA expression levels significantly increased in $24 \mathrm{~h}$ p.r. infected neurons with respect to matched CTRL and $24 \mathrm{~h}$ p.i. neurons (Figure 2c), suggesting that a cycle of HSV-1 latency and reactivation may contribute to accelerate aging. In addition, HIRA levels also increased in control neurons within the days in culture, confirming that the expression of this protein normally increases during aging. Moreover, we did not observe any significant change in HIRA levels $24 \mathrm{~h}$ p.i. This latter result is in line with McFarlane et al. showing that ICP0 disrupts nuclear localization of HIRA without inducing its proteasome-dependent degradation in several non-neuronal cell lines during HSV-1 productive infection [41]. However, in mouse brains, we found that 3 cycles of viral reactivation resulted in a significant decrease of HIRA expression (Figure 5), whereas a slight decrease was observed following 7 reactivations (Figures 5 and 6). On the contrary, in Pre 7TS HSV1-M brains HIRA was found significantly increased with respect to CTRL-M. This discrepancy between the in vitro and in vivo results may be due to the in vitro model limitations: the number of reactivations induced (1 TS vs. 3 TS/7 TS) could also influence the viral copy number/viral load causing a more dramatic decrease in HIRA levels in vivo and the in vitro latency establishment. Indeed, a recent study by Powell-Doherty and colleagues has shown that $\mathrm{ACV}$ administration on hippocampal neuronal culture induced a "quiescent infection", just preventing viral replication instead of an actual latent state establishment. In this perspective, it is possible to argue that the HIRA increase in 24 p.r. infected neurons is a result of an accumulation of HIRA due to the maintenance of the quiescent state [58]. Taken together, these results showed that recurrent HSV-1 infection induces the degradation of HIRA protein only within the active replication of the virus, whereas during latency, the expression of the protein is upregulated. It is noteworthy that a similar trend was also observed for H3K56ac, which is known to be induced by ASF1, a cellular protein associated with HIRA only during senescence. It is possible to speculate that the increase of HIRA may hijack ASF1 to the SAHF/PML-NB, indirectly inducing the increase of H3K56ac that we found in Pre 7TS mice when the virus is still latent and is localized in PML bodies. Notable, in HSV1-M brains HIRA was found localized perinuclearly, where it probably also retains the viral genome and the PML-NB (Figure 6).

In summary, our data indicate that HSV-1 harboring neurons may accumulate markers of senescence such as H4K16 hyperacetylation and HIRA protein, together with the increase in Sin3/HDAC1, that may accelerate neuronal aging. Altogether these results strongly suggest that recurrent HSV-1 infection can accelerate pathological aging of neurons through the modulation/regulation of these proteins/mechanisms thus contributing to neurodegeneration. 


\section{Materials and Methods}

\subsection{Virus Production and Titration}

HSV-1 (F strain, wild-type) production was performed on monolayers of African green monkey kidney cells (VERO, ATCC) cultivated in $75 \mathrm{~cm}^{2}$ tissue culture flasks and infected a multiplicity of infection (M.O.I.) of 0.01 . After $48 \mathrm{~h}$ at $37^{\circ} \mathrm{C}, \mathrm{HSV}-1$-infected cells were harvested, and following 3 freeze/thaw cycles, cell debris were removed with low-speed centrifugation. Then the supernatant containing new virions was collected and titred by Standard Plaque Assay (SPA) as plaque-forming unit (PFU) per $\mathrm{ml}(\mathrm{PFU} / \mathrm{mL})$ on confluent VERO monolayer in 24-wells plates [59]. Briefly, after the adsorption phase (1 h, $37^{\circ} \mathrm{C}$ ), the supernatants were discarded, and the medium was replaced with RPMI medium (Sigma-Aldrich, St Louis, MO, USA) supplemented with $2 \%$ heat-inactivated Fetal Bovine Serum (FBS, Gibco, Thermo Fisher Scientific, Waltham, MA, USA) and $\%$ carboxymethyl cellulose (CMC, Sigma-Aldrich, St Louis, MO, USA), to contain the virus infection. After $48 \mathrm{~h}$, VERO was subjected to a washing-step in Dulbecco's Phosphate Buffered Saline (PBS, w/o Calcium chloride and Magnesium chloride, Sigma-Aldrich, St Louis, MO, USA), fixed in absolute methanol and colored with crystal violet (Sigma-Aldrich, St Louis, MO, USA) to evaluate the plaque formation. In this study, the virus had a titer of $1 \times 10^{9} \mathrm{PFU} / \mathrm{mL}$. Similarly, a Mock-solution (Mock) was prepared from not infected VERO cells.

\subsection{Neuronal in Vitro Model of Recurrent HSV-1 Infection}

Primary cultures of cortical neurons were prepared from E17 WISTAR rat embryos (Charles Rivers Laboratories International, Inc., Wilmington, MA, US), as described in [46,55] with minor modification. Briefly, embryos were decapitated to separate the head from the rest of the body, then the brains were dissected to isolate the cortices. Cortices deprived of meninges were collected in cold PBS, and then incubated for $15 \mathrm{~min}$ at $37{ }^{\circ} \mathrm{C}$ in trypsinEDTA $(0.025 \% / 0.01 \% w / v ; 500 \mu \mathrm{L} /$ cortices pair; Gibco, Thermo Fisher Scientific, Waltham, MA, USA). After blocking the trypsin with FBS, the tissues were mechanically dissociated at room temperature (RT) with a sterilized Pasteur pipette, and the cell suspension was centrifuged (1200 rpm, $3 \mathrm{~min})$. The pellet was suspended in complete MEM medium ( $5 \%$ FBS, $5 \%$ horse serum, $1 \%$ glutamine $(2 \mathrm{mM}), 1 \%$ penicillin-streptomycin-neomycin antibiotic cocktail (PSN), and glucose (25 mM); Sigma- Aldrich, St Louis, MO, USA). Cells were plated at a density of $1 \times 10^{6}$ cells on precoated 6 well-plates (coating: poly-L-lysine $0.1 \mathrm{mg} / \mathrm{mL}$; Sigma-Aldrich, St Louis, MO, USA) and kept in a $37{ }^{\circ} \mathrm{C}, 5 \% \mathrm{CO}_{2}$ humidified incubator. After 4 hours, the culture medium was replaced with Neurobasal medium (Gibco, Thermo Fisher Scientific, Waltham, MA, USA) containing 2\% B-27 (Invitrogen, Carlsbad, CA, USA), $0.5 \%$ glutamine $(2 \mathrm{mM})$, and $1 \%$ PSN. The day after (day in vitro 1 , DIV 1$)$, the medium was supplemented with $5 \mu \mathrm{M}$ cytosine arabinoside (Ara-C, Sigma-Aldrich, St Louis, MO, USA) to prevent glial proliferation and obtain a pure neuronal culture. Four days after plating (DIV 4), the medium was replaced with glutamine-free Neurobasal medium supplemented with $2 \%$ B-27 and 1\% PSN. Neurons were cultured for 6-7 days, with half the medium refreshed every $48 \mathrm{~h}$, before experiments could be carried out.

At DIV 6, except for an untreated maintenance plate, neuronal cultures were separated into 2 main experimental groups: $24 \mathrm{~h}$ post-infection (p.i.) and $24 \mathrm{~h}$ post reactivation (24 h p.r.; 11 days p.i.). The medium of the second group was supplemented with $50 \mu \mathrm{M}$ acycloguanosine (ACV, Sigma-Aldrich, St Louis, MO, USA) for $18 \mathrm{~h}$ before infection $\left(37^{\circ} \mathrm{C}\right.$, $5 \% \mathrm{CO}_{2}$ ). At DIV 7, the neuronal cultures were Mock- or HSV-1-infected (0.1 M.O.I.) in the Neurobasal medium (adsorption phase; $1 \mathrm{~h}$ and $30 \mathrm{~min}, 37^{\circ} \mathrm{C}$ ). Then, the medium was removed and, after a wash in PBS. The cells were returned to the original medium $(+/-\mathrm{ACV})$ and cultured for $24 \mathrm{~h}$ or 11 days. The $24 \mathrm{~h}$ p.i. neurons were harvested and collected for protein extraction (see below). The $24 \mathrm{~h}$ p.r. neurons medium was refreshed every 2-3 days and supplemented with $50 \mu \mathrm{M} \mathrm{ACV}$, to keep the virus in the latent state in the HSV-1-infected one at DIV 17 (d.p.i. 10), the medium was replaced to ensure ACV depletion with half of conditioned-Neurobasal medium, obtained from the matched maintenance plate, and half of fresh medium. Then, the cultures were subjected to a 
Thermal Stress (TS) cycle to induce viral reactivation by using a constant-temperature water bath set at $43^{\circ} \mathrm{C}$ for $10 \mathrm{~min}$. Mock-infected neurons underwent a superimposable protocol (ACV treatment and TS). No sign of neuronal death or distress was observed after this procedure. A total of 24 hours later, the neurons were harvested. The supernatants were collected $24 \mathrm{~h}$ p.i., $24 \mathrm{~h}$ p.r., and at every medium-refresh step and analyzed by SPA, to evaluate the viral titer and the viral latency/reactivation. Supernatants from representative experiments were also analyzed by In Cell Western (ICW) to quantify virus titer (Supplementary Figure S1), as described in [60].

\subsection{Mouse Model of Recurrent HSV-1 Infection and Experimental Groups}

To investigate the aging markers, we used the brain tissues from the mouse model of recurrent HSV-1 infection previously set up and virologically characterized in our group, as thoroughly described in De Chiara et al. 2019 [3]. Briefly, 6-8-week-old female BALB/c mice had been housed in the animal house (Istituto Superiore di Sanità, Rome, Italy) and has been kept under a $12 \mathrm{~h}$ light/dark cycle at RT with free access to food and water. A group of mice was HSV-1- inoculated (suspension equivalent to $10^{6} \mathrm{PFU} / \mathrm{mL}$ ) by snout abrasion to establish the first experimental group named HSV1-M, following anesthesia with a Ketamine $(80 \mathrm{mg} / \mathrm{Kg}) /$ Xylazine $(5 \mathrm{mg} / \mathrm{Kg})$ cocktail intraperitoneally injected. At the same time, a set of mice was analogously inoculated with the Mock-solution constituting the CTRL-M group and was kept in separated cages. A first group of mice was sacrificed 4 days post-infection ( 4 d.p.i., i.e., when the virus actively replicates), whereas, after the establishment of latent infection ( 6 weeks p.i.), the other mice underwent to repeated cycles of TS throughout their life (up to 7 times) to induce viral reactivation. Then, mice were analyzed at specific timepoints: (i) at 4 d.p.i (CTRL-M $n=3$ and HSV1-M $n=5$ ) (ii) after the 3rd TS (Post 3TS, CTRL-M $n=3$ and HSV1-M $n=4 ; 6$-months-old); (iii) $24 \mathrm{~h}$ before the 7th TS (Pre 7TS, CTRL-M $n=4$ and HSV1-M $n=4$; 13-months-old); (iv) $24 \mathrm{~h}$ after the 7th TS (Post 7TS, CTRL-M $n=4$ and HSV1-M $n=4$; same age of the Pre 7TS).

\subsection{Ethics Statement}

All the experimental protocols of the present study were in compliance with the European Guide for the Care and Use of Laboratory Animals and institutional guidelines and with the Italian legislation on animal experimentation (Decreto legislativo n. 26/2014, Direttiva UE 63/2010) to avoid any unnecessary distress during the experimental procedures. The experimental protocols were reviewed by the Animal Welfare Body (Istituto Superiore Sanità) and authorized by the Italian Ministry of Health (protocol numbers 801/2016-B, 745/2016-PR).

\subsection{Western Blotting}

Neuronal cultures were harvested and lysed in $300 \mu \mathrm{L}$ RIPA buffer $(20 \mathrm{mM}$ Tris, $150 \mathrm{mM} \mathrm{NaCl}, 1 \%$ Triton X-100, 1\% sodium deoxycholate, $0.1 \%$ SDS) containing $5 \mu \mathrm{M}$ Sodium Butyrate and protease and phosphatase inhibitors cocktails (Sigma-Aldrich, St Louis, $\mathrm{MO}$, USA). Cortices, after dissection, were stored at $-80^{\circ} \mathrm{C}$ until use and were homogenized on ice using a potter (15-25 strokes), in 5 volumes of complete RIPA. The neuronal and cortical proteins in RIPA were sonicated at low power setting on ice (3 pulse $\times 3 \mathrm{~s}$ ), and then separated by centrifugation at $14,000 \mathrm{rpm}$ at $4{ }^{\circ} \mathrm{C}$ for $20 \mathrm{~min}$. Total protein concentrations were measured with Micro BCA method (Thermo Fisher Scientific, Waltham, MA, USA). An equal amount of protein samples $(30 \mu \mathrm{g})$ was separated by $7.6-15 \%$ SDSPAGE and blotted onto 0.22/0.45 $\mu \mathrm{m}$ nitrocellulose membrane (Bio-Rad, Hercules, CA, USA; GE Healthcare, Cytiva, Marlborough, MA, USA). Membranes were colored with Ponceau Red (Sigma-Aldrich, St Louis, MO, USA) and, after washing with TBS, blocked in $10 \%$ non-fat milk (1-3 h), in 0.1\% Tween-20 TBS (T-TBS). Then the filters were incubated overnight at $4{ }^{\circ} \mathrm{C}$ with the primary antibody $(\mathrm{Ab})$ diluted in $5 \%$ non-fat milk in T-TBS. We used the following dilution for primary Abs: Anti-HIRA 1:1000 (\#12463, Cell Signaling Technology, Danvers, MA, USA),), Anti-H3K56ac 1:1000 (\#4243S, Cell Signaling Technology, 
Danvers, MA, USA), Anti-H4K16ac 1:1000 (\#13534, Cell Signaling Technology, Danvers, MA, USA); Anti-H3 1:2500 (\#1791, Abcam, Cambridge, UK); Anti-Sin3 1:200 (sc-5299, SantaCruz, Biotechnology, Heidelberg, Germany), Anti-HDAC1 1:1000 (sc-81598, Santa-Cruz, Biotechnology, Heidelberg, Germany); Anti- $\beta$-Actin 1:5000 (A2228, Sigma-Aldrich, St Louis, MO, USA). After $3 \times 10 \mathrm{~min}$ washes with T-TBS, the membranes and incubated $1 \mathrm{~h}$ with secondary $\mathrm{Ab}$ (HRP-conjugated antibodies, Jackson ImmunoResearch Laboratories, West Grove, PA, USA), followed by $3 \times 10 \mathrm{~min}$ washes in T-TBS. The chemiluminescence reaction was obtained using Clarity or Clarity Max Western ECL Substrate (Bio-Rad, Hercules, CA, USA) and detected by film impression or Chemidoc Imaging System (Bio-Rad, Hercules, CA, USA). Densitometric analysis was performed using Quantity One software or ImageLab software (Bio-Rad, Hercules, CA, USA). The integrated density, corrected for non-specific background, was normalized to equal loading housekeeping protein ( $\beta$-Actin, or $\mathrm{H} 3$ ) and averaged per animal for mice analyses. These values were included in the statistical analysis. Finally, we chose histone H3 as load control for all the analyzed histones PTMs since H3 and $\mathrm{H} 4$ are obligate heterodimers and are stoichiometrically equal in chromatin occupancy.

\subsection{Immunofluorescence Analysis}

Slices samples used were previously obtained from our group [3]. Briefly, after anesthesia with an intraperitoneal injection of a Ketamine $(200 \mathrm{mg} / \mathrm{Kg})$ and Xylazine $(10 \mathrm{mg} / \mathrm{Kg})$ cocktail, each mouse was immobilized and transcardially perfused with PBS (pH 7.4), and with $4 \%$ paraformaldehyde (PFA). The brains were fixed for $24 \mathrm{~h}$ at $4{ }^{\circ} \mathrm{C}$ in PFA, followed by cryoprotection in 15-30\% sucrose gradient in PBS. A total of $40-\mu \mathrm{m}$-thick coronal slices were cut and stored at $-20{ }^{\circ} \mathrm{C}$ in cryoprotectant solution $(\mathrm{pH} 7.450 \mathrm{mM}$ sodium phosphate buffer, $15 \%$ glucose, $30 \%$ ethylene glycol) until use. For this study, 2 slices for each mouse were used, washed in PBS and permeabilized (0.5\% Triton X-100 in PBS) for $15 \mathrm{~min}$ at RT. After the samples were blocked with blocking solution $(10 \%$ horse serum, $0.2 \%$ Triton X-100 in PBS, RT) for 90 min to avoid unspecific Abs binding, the slices were incubated overnight with the chosen primary $\mathrm{Ab}$ ( $5 \%$ horse serum, $0.2 \%$ Triton X-100 PBS, $+4^{\circ} \mathrm{C}$ ). The following dilutions were used: 1:200 anti-HIRA Ab (\#12463, Cell Signaling Technology, Danvers, MA, USA); 1:300 anti-NeuN Ab (MAB377, SantaCruz Biotechnology, Heidelberg, Germany). Slices undergone to 3 washing steps (PBS), and incubated for $90 \mathrm{~min}$ at RT with specific secondary Abs coupled to Alexa 488 or Alexa 546 (1:1000, Invitrogen). After 3 washes in PBS, slices were stained with DAPI (1:500 dilution in PBS) for $20 \mathrm{~min}$ at RT, briefly washed, dried, and then mounted on a coverslip with mounting medium (ProLong Gold Anti-fade reagent, Invitrogen, Carlsbad, CA, USA). Images were acquired at $40 \times$ magnification with a confocal laser scanning system (Leica Microsystems TCS-SP2, Wetzlar, Germany) and an oil-immersion objective (N.A. 1.4). Quantifications of image intensity were carried out by Imaris suite 7.4 software (Bitplane A.G., Zurich, Switzerland) in neocortical areas of the slices. The "Surface module" was used to automatically draw a mask on NeuN positive cells (red channel) to identify neurons, and then the mean pixel intensity of HIRA (green channel) was evaluated in neuronal cells. For inset images, an additional $10 \times$ magnification was applied.

\subsection{Statistical Analyses}

Data were analyzed by Mann-Whitney test, multiple Student's $t$-test, two-way ANOVA model, when appropriate, using the statistical software Graphpad Prism v. 6.0. Experiments were repeated up to 3 times. Post-hoc comparisons were performed using Tukey's honest significance test [61] and outliers were identified by using the Grubbs test and omitted from the analyses [62]. Data were presented as mean \pm standard error of the mean (SEM). The level of significance (alpha) was set at 0.05 .

Supplementary Materials: The following are available online at https://www.mdpi.com/article/10 $.3390 /$ ijms22126279/s1. 
Author Contributions: Conceptualization, G.N., G.D.C., A.T.P.; methodology. G.D.C., G.N., V.P.; formal analysis, G.N., G.D.C.; investigation G.N., V.P., M.E.M.; resources G.D.C., A.T.P.; writingoriginal draft preparation, G.N., G.D.C.; writing-review and editing, L.N., G.D.C., A.T.P., visualization, G.N.; supervision, G.D.C., A.T.P.; project administration, G.D.C., A.T.P.; funding acquisition, G.D.C., M.E.M., G.N. All authors have read and agreed to the published version of the manuscript.

Funding: This work was funded by the Italian Ministry of Instruction, University and Research, grant number PRIN20179JHAMZ_006 to G.D.C. and by Ateneo 2019 (RP11916B8696E5EC) to M.E.M. and Ateneo 2017 (AR11715C7DF6F0A7) to G.N.

Institutional Review Board Statement: All the experimental protocols of the present study are in compliance with the European Guide for the Care and Use of Laboratory Animals and institutional guidelines and with the Italian legislation on animal experimentation (Decreto legislativo n. 26/2014, Direttiva UE 63/2010), to avoid any unnecessary distress during the experimental procedures. The experimental protocols were reviewed by the Animal Welfare Body (Istituto Superiore Sanità) and authorized by the Italian Ministry of Health (protocol numbers 801/2016-B, 745/2016-PR).

Informed Consent Statement: Not applicable.

Data Availability Statement: All relevant data are within the manuscript and its Supplementary Information files.

Acknowledgments: The authors acknowledge Mauro Valeri, Andrea Martinelli and Flavio Torriani (Istituto Superiore di Sanità, Animal House) for their valuable animal care support.

Conflicts of Interest: The authors declare no conflict of interest. The funder had no role in study design, data collection and analysis, decision to publish, or preparation of the manuscript.

\section{References}

1. Marcocci, M.E.; Napoletani, G.; Protto, V.; Kolesova, O.; Piacentini, R.; Li Puma, D.D.; Lomonte, P.; Grassi, C.; Palamara, A.T.; De Chiara, G. Herpes Simplex Virus-1 in the Brain: The Dark Side of a Sneaky Infection. Trends Microbiol. 2020, 28, 808-820. [CrossRef]

2. Roizman, B.; Knipe, D.M.; Whitley, R.J. Herpes Simplex Viruses. In Fields Virology, 6th ed.; Howley, D.M.K.P.M., Ed.; Lippincott Williams \& Wilkins, a Wolters Kluwer Business: Alphen aan den Rijn, The Netherlands, 2014.

3. De Chiara, G.; Piacentini, R.; Fabiani, M.; Mastrodonato, A.; Marcocci, M.E.; Limongi, D.; Napoletani, G.; Protto, V.; Coluccio, P.; Celestino, I.; et al. Recurrent herpes simplex virus-1 infection induces hallmarks of neurodegeneration and cognitive deficits in mice. PLoS Pathog. 2019, 15, e1007617. [CrossRef]

4. Kastrukoff, L.; Hamada, T.; Schumacher, U.; Long, C.; Doherty, P.C.; Koprowski, H. Central nervous system infection and immune response in mice inoculated into the lip with herpes simplex virus type 1. J. Neuroimmunol. 1982, 2, 295-305. [CrossRef]

5. Kramer, M.F.; Cook, W.J.; Roth, F.P.; Zhu, J.; Holman, H.; Knipe, D.M.; Coen, D.M. Latent herpes simplex virus infection of sensory neurons alters neuronal gene expression. J. Virol. 2003, 77, 9533-9541. [CrossRef] [PubMed]

6. De Chiara, G.; Marcocci, M.E.; Sgarbanti, R.; Civitelli, L.; Ripoli, C.; Piacentini, R.; Garaci, E.; Grassi, C.; Palamara, A.T. Infectious agents and neurodegeneration. Mol. Neurobiol. 2012, 46, 614-638. [CrossRef] [PubMed]

7. Piacentini, R.; De Chiara, G.; Li Puma, D.D.; Ripoli, C.; Marcocci, M.E.; Garaci, E.; Palamara, A.T.; Grassi, C. HSV-1 and Alzheimer's disease: More than a hypothesis. Front. Pharmacol. 2014, 5, 97. [CrossRef]

8. Itzhaki, R.F. Corroboration of a Major Role for Herpes Simplex Virus Type 1 in Alzheimer's Disease. Front. Aging Neurosci. 2018, 10, 324. [CrossRef]

9. Lovheim, H.; Gilthorpe, J.; Adolfsson, R.; Nilsson, L.G.; Elgh, F. Reactivated herpes simplex infection increases the risk of Alzheimer's disease. Alzheimer's Dement. J. Alzheimer's Assoc. 2015, 11, 593-599. [CrossRef]

10. Lovheim, H.; Norman, T.; Weidung, B.; Olsson, J.; Josefsson, M.; Adolfsson, R.; Nyberg, L.; Elgh, F. Herpes Simplex Virus, APOEvarepsilon4, and Cognitive Decline in Old Age: Results from the Betula Cohort Study. J. Alzheimers Dis. 2019, 67, 211-220. [CrossRef] [PubMed]

11. Protto, V.; Tramutola, A.; Fabiani, M.; Marcocci, M.E.; Napoletani, G.; Iavarone, F.; Vincenzoni, F.; Castagnola, M.; Perluigi, M.; Di Domenico, F.; et al. Multiple Herpes Simplex Virus-1 (HSV-1) Reactivations Induce Protein Oxidative Damage in Mouse Brain: Novel Mechanisms for Alzheimer's Disease Progression. Microorganisms 2020, 8, 972. [CrossRef]

12. Carter, C.J. Susceptibility genes are enriched in those of the herpes simplex virus $1 /$ host interactome in psychiatric and neurological disorders. Pathog. Dis. 2013, 69, 240-261. [CrossRef] [PubMed]

13. Virtanen, J.O.; Jacobson, S. Viruses and multiple sclerosis. CNS Neurol. Disord. Drug. Targets 2012, 11, 528-544. [CrossRef] [PubMed]

14. Leibovitch, E.C.; Caruso, B.; Ha, S.K.; Schindler, M.K.; Lee, N.J.; Luciano, N.J.; Billioux, B.J.; Guy, J.R.; Yen, C.; Sati, P.; et al. Herpesvirus trigger accelerates neuroinflammation in a nonhuman primate model of multiple sclerosis. Proc. Natl. Acad. Sci. USA 2018, 115, 11292-11297. [CrossRef] [PubMed] 
15. Boukhvalova, M.S.; Mortensen, E.; Mbaye, A.; Lopez, D.; Kastrukoff, L.; Blanco, J.C.G. Herpes Simplex Virus 1 Induces Brain Inflammation and Multifocal Demyelination in the Cotton Rat Sigmodon hispidus. J. Virol. 2019, 94, e01161-19. [CrossRef]

16. Franceschi, C.; Garagnani, P.; Morsiani, C.; Conte, M.; Santoro, A.; Grignolio, A.; Monti, D.; Capri, M.; Salvioli, S. The Continuum of Aging and Age-Related Diseases: Common Mechanisms but Different Rates. Front. Med. 2018, 5, 61. [CrossRef]

17. Niccoli, T.; Partridge, L. Ageing as a risk factor for disease. Curr. Biol. 2012, 22, R741-R752. [CrossRef]

18. He, N.; Jin, W.L.; Lok, K.H.; Wang, Y.; Yin, M.; Wang, Z.J. Amyloid-beta(1-42) oligomer accelerates senescence in adult hippocampal neural stem/progenitor cells via formylpeptide receptor 2. Cell Death Dis. 2013, 4, e924. [CrossRef]

19. Jurk, D.; Wang, C.; Miwa, S.; Maddick, M.; Korolchuk, V.; Tsolou, A.; Gonos, E.S.; Thrasivoulou, C.; Saffrey, M.J.; Cameron, K.; et al. Postmitotic neurons develop a p21-dependent senescence-like phenotype driven by a DNA damage response. Aging Cell 2012, 11, 996-1004. [CrossRef]

20. Ohashi, M.; Korsakova, E.; Allen, D.; Lee, P.; Fu, K.; Vargas, B.S.; Cinkornpumin, J.; Salas, C.; Park, J.C.; Germanguz, I.; et al. Loss of MECP2 Leads to Activation of P53 and Neuronal Senescence. Stem Cell Rep. 2018, 10, 1453-1463. [CrossRef]

21. Sedelnikova, O.A.; Horikawa, I.; Zimonjic, D.B.; Popescu, N.C.; Bonner, W.M.; Barrett, J.C. Senescing human cells and ageing mice accumulate DNA lesions with unrepairable double-strand breaks. Nat. Cell Biol. 2004, 6, 168-170. [CrossRef]

22. Arendt, T.; Holzer, M.; Gartner, U. Neuronal expression of cycline dependent kinase inhibitors of the INK4 family in Alzheimer's disease. J. Neural. Transm. 1998, 105, 949-960. [CrossRef]

23. Arendt, T.; Rodel, L.; Gartner, U.; Holzer, M. Expression of the cyclin-dependent kinase inhibitor p16 in Alzheimer's disease Neuroreport 1996, 7, 3047-3049. [CrossRef] [PubMed]

24. Bhat, R.; Crowe, E.P.; Bitto, A.; Moh, M.; Katsetos, C.D.; Garcia, F.U.; Johnson, F.B.; Trojanowski, J.Q.; Sell, C.; Torres, C. Astrocyte senescence as a component of Alzheimer's disease. PLoS ONE 2012, 7, e45069. [CrossRef] [PubMed]

25. O'Sullivan, R.J.; Kubicek, S.; Schreiber, S.L.; Karlseder, J. Reduced histone biosynthesis and chromatin changes arising from a damage signal at telomeres. Nat. Struct. Mol. Biol. 2010, 17, 1218-1225. [CrossRef] [PubMed]

26. Nativio, R.; Donahue, G.; Berson, A.; Lan, Y.; Amlie-Wolf, A.; Tuzer, F.; Toledo, J.B.; Gosai, S.J.; Gregory, B.D.; Torres, C.; et al. Dysregulation of the epigenetic landscape of normal aging in Alzheimer's disease. Nat. Neurosci. 2018, 21, 497-505. [CrossRef]

27. O'Sullivan, R.J.; Karlseder, J. The great unravelling: Chromatin as a modulator of the aging process. Trends Biochem. Sci. 2012, 37, 466-476. [CrossRef]

28. Miller, K.M.; Tjeertes, J.V.; Coates, J.; Legube, G.; Polo, S.E.; Britton, S.; Jackson, S.P. Human HDAC1 and HDAC2 function in the DNA-damage response to promote DNA nonhomologous end-joining. Nat. Struct Mol. Biol. 2010, 17, 1144-1151. [CrossRef]

29. Adams, G.E.; Chandru, A.; Cowley, S.M. Co-repressor, co-activator and general transcription factor: The many faces of the Sin 3 histone deacetylase (HDAC) complex. Biochem. J. 2018, 475, 3921-3932. [CrossRef]

30. Bardai, F.H.; Price, V.; Zaayman, M.; Wang, L.; D'Mello, S.R. Histone deacetylase-1 (HDAC1) is a molecular switch between neuronal survival and death. J. Biol. Chem. 2012, 287, 35444-35453. [CrossRef]

31. Kim, J.Y.; Shen, S.; Dietz, K.; He, Y.; Howell, O.; Reynolds, R.; Casaccia, P. HDAC1 nuclear export induced by pathological conditions is essential for the onset of axonal damage. Nat. Neurosci. 2010, 13, 180-189. [CrossRef]

32. Gilbert, T.M.; Zurcher, N.R.; Catanese, M.C.; Tseng, C.J.; Di Biase, M.A.; Lyall, A.E.; Hightower, B.G.; Parmar, A.J.; Bhanot, A.; Wu, C.J.; et al. Neuroepigenetic signatures of age and sex in the living human brain. Nat. Commun. 2019, 10, 2945. [CrossRef]

33. Ray-Gallet, D.; Ricketts, M.D.; Sato, Y.; Gupta, K.; Boyarchuk, E.; Senda, T.; Marmorstein, R.; Almouzni, G. Functional activity of the H3.3 histone chaperone complex HIRA requires trimerization of the HIRA subunit. Nat. Commun. 2018, 9, 3103. [CrossRef] [PubMed]

34. Ricketts, M.D.; Marmorstein, R. A Molecular Prospective for HIRA Complex Assembly and H3.3-Specific Histone Chaperone Function. J. Mol. Biol. 2017, 429, 1924-1933. [CrossRef] [PubMed]

35. Zhang, R.; Poustovoitov, M.V.; Ye, X.; Santos, H.A.; Chen, W.; Daganzo, S.M.; Erzberger, J.P.; Serebriiskii, I.G.; Canutescu, A.A.; Dunbrack, R.L.; et al. Formation of MacroH2A-containing senescence-associated heterochromatin foci and senescence driven by ASF1a and HIRA. Dev. Cell 2005, 8, 19-30. [CrossRef] [PubMed]

36. Banumathy, G.; Somaiah, N.; Zhang, R.; Tang, Y.; Hoffmann, J.; Andrake, M.; Ceulemans, H.; Schultz, D.; Marmorstein, R.; Adams, P.D. Human UBN1 is an ortholog of yeast Hpc2p and has an essential role in the HIRA/ASF1a chromatin-remodeling pathway in senescent cells. Mol. Cell Biol. 2009, 29, 758-770. [CrossRef] [PubMed]

37. Rai, T.S.; Adams, P.D. Lessons from senescence: Chromatin maintenance in non-proliferating cells. Biochim. Biophys. Acta 2012, 1819, 322-331. [CrossRef] [PubMed]

38. Everett, R.D.; Rechter, S.; Papior, P.; Tavalai, N.; Stamminger, T.; Orr, A. PML contributes to a cellular mechanism of repression of herpes simplex virus type 1 infection that is inactivated by ICP0. J. Virol. 2006, 80, 7995-8005. [CrossRef]

39. Rai, T.S.; Glass, M.; Cole, J.J.; Rather, M.I.; Marsden, M.; Neilson, M.; Brock, C.; Humphreys, I.R.; Everett, R.D.; Adams, P.D. Histone chaperone HIRA deposits histone H3.3 onto foreign viral DNA and contributes to anti-viral intrinsic immunity. Nucleic Acids Res. 2017, 45, 11673-11683. [CrossRef]

40. Zhang, Y.; Jiang, C.; Trudeau, S.J.; Narita, Y.; Zhao, B.; Teng, M.; Guo, R.; Gewurz, B.E. Histone Loaders CAF1 and HIRA Restrict Epstein-Barr Virus B-Cell Lytic Reactivation. mBio 2020, 11, e01063-20. [CrossRef]

41. McFarlane, S.; Orr, A.; Roberts, A.P.E.; Conn, K.L.; Iliev, V.; Loney, C.; da Silva Filipe, A.; Smollett, K.; Gu, Q.; Robertson, N.; et al. The histone chaperone HIRA promotes the induction of host innate immune defences in response to HSV-1 infection. PLoS Pathog. 2019, 15, e1007667. [CrossRef] 
42. Horvath, S.; Levine, A.J. HIV-1 Infection Accelerates Age According to the Epigenetic Clock. J. Infect. Dis. 2015, 212, 1563-1573. [CrossRef] [PubMed]

43. Naggie, S. Hepatitis C Virus, Inflammation, and Cellular Aging: Turning Back Time. Top. Antivir. Med. 2017, 25, 3-6. [PubMed]

44. Naggie, S.; Swiderska-Syn, M.; Choi, S.; Lusk, S.; Lan, A.; Ferrari, G.; Syn, W.K.; Guy, C.D.; Diehl, A.M. Markers of Tissue Repair and Cellular Aging Are Increased in the Liver Tissue of Patients With HIV Infection Regardless of Presence of HCV Coinfection. Open Forum Infect. Dis. 2018, 5, ofy138. [CrossRef] [PubMed]

45. Stowe, R.P.; Peek, M.K.; Cutchin, M.P.; Goodwin, J.S. Reactivation of herpes simplex virus type 1 is associated with cytomegalovirus and age. J. Med. Virol. 2012, 84, 1797-1802. [CrossRef]

46. Kobayashi, M.; Kim, J.Y.; Camarena, V.; Roehm, P.C.; Chao, M.V.; Wilson, A.C.; Mohr, I. A primary neuron culture system for the study of herpes simplex virus latency and reactivation. J. Vis. Exp. 2012, 3823. [CrossRef]

47. Feser, J.; Tyler, J. Chromatin structure as a mediator of aging. FEBS Lett. 2011, 585, 2041-2048. [CrossRef]

48. Cohen, C.; Corpet, A.; Roubille, S.; Maroui, M.A.; Poccardi, N.; Rousseau, A.; Kleijwegt, C.; Binda, O.; Texier, P.; Sawtell, N.; et al. Promyelocytic leukemia (PML) nuclear bodies (NBs) induce latent/quiescent HSV-1 genomes chromatinization through a PML NB/Histone H3.3/H3.3 Chaperone Axis. PLoS Pathog. 2018, 14, e1007313. [CrossRef]

49. Michishita, E.; McCord, R.A.; Boxer, L.D.; Barber, M.F.; Hong, T.; Gozani, O.; Chua, K.F. Cell cycle-dependent deacetylation of telomeric histone H3 lysine K56 by human SIRT6. Cell Cycle 2009, 8, 2664-2666. [CrossRef]

50. Feser, J.; Truong, D.; Das, C.; Carson, J.J.; Kieft, J.; Harkness, T.; Tyler, J.K. Elevated histone expression promotes life span extension. Mol. Cell 2010, 39, 724-735. [CrossRef]

51. Kulej, K.; Avgousti, D.C.; Sidoli, S.; Herrmann, C.; Della Fera, A.N.; Kim, E.T.; Garcia, B.A.; Weitzman, M.D. Time-resolved Global and Chromatin Proteomics during Herpes Simplex Virus Type 1 (HSV-1) Infection. Mol. Cell Proteom. 2017, 16, S92-S107. [CrossRef] [PubMed]

52. Contrepois, K.; Thuret, J.Y.; Courbeyrette, R.; Fenaille, F.; Mann, C. Deacetylation of H4-K16Ac and heterochromatin assembly in senescence. Epigenetics Chromatin 2012, 5, 15. [CrossRef]

53. Panossian, L.; Fenik, P.; Zhu, Y.; Zhan, G.; McBurney, M.W.; Veasey, S. SIRT1 regulation of wakefulness and senescence-like phenotype in wake neurons. J. Neurosci. 2011, 31, 4025-4036. [CrossRef]

54. Martin, C.; Leyton, L.; Arancibia, Y.; Cuevas, A.; Zambrano, A.; Concha, M.I.; Otth, C. Modulation of the AMPK/Sirt1 axis during neuronal infection by herpes simplex virus type 1. J. Alzheimers Dis. 2014, 42, 301-312. [CrossRef]

55. De Chiara, G.; Racaniello, M.; Mollinari, C.; Marcocci, M.E.; Aversa, G.; Cardinale, A.; Giovanetti, A.; Garaci, E.; Palamara, A.T.; Merlo, D. Herpes Simplex Virus-Type1 (HSV-1) Impairs DNA Repair in Cortical Neurons. Front. Aging Neurosci. $2016,8,242$. [CrossRef]

56. Rielland, M.; Cantor, D.J.; Graveline, R.; Hajdu, C.; Mara, L.; Diaz Bde, D.; Miller, G.; David, G. Senescence-associated SIN3B promotes inflammation and pancreatic cancer progression. J. Clin. Investig. 2014, 124, 2125-2135. [CrossRef]

57. Rai, T.S.; Cole, J.J.; Nelson, D.M.; Dikovskaya, D.; Faller, W.J.; Vizioli, M.G.; Hewitt, R.N.; Anannya, O.; McBryan, T.; Manoharan, I.; et al. HIRA orchestrates a dynamic chromatin landscape in senescence and is required for suppression of neoplasia. Genes Dev. 2014, 28, 2712-2725. [CrossRef] [PubMed]

58. Powell-Doherty, R.D.; Abbott, A.R.N.; Nelson, L.A.; Bertke, A.S. Amyloid-beta and p-Tau Anti-Threat Response to Herpes Simplex Virus 1 Infection in Primary Adult Murine Hippocampal Neurons. J. Virol. 2020, 94, e01874-19. [CrossRef] [PubMed]

59. Killington, R.A. Growth, assay and purification of Herpes viruses. In Virology a Practical Approach; Mahy, B.W.J., Ed.; IRL Press: Oxford, UK, 1991; pp. 207-236.

60. Fabiani, M.; Limongi, D.; Palamara, A.T.; De Chiara, G.; Marcocci, M.E. A Novel Method to Titrate Herpes Simplex Virus-1 (HSV-1) Using Laser-Based Scanning of Near-Infrared Fluorophores Conjugated Antibodies. Front. Microbiol. 2017, 8, 1085. [CrossRef] [PubMed]

61. Brillinger, D. The Collected Works of John W. Tukey; Wadsworth Advanced Books \& Software: Monterey, CA, USA, 1984.

62. Grubbs, F.E. Procedures for Detecting Outlying Observations in Samples. Technometrics 1969, 11, 1-21. [CrossRef] 